\title{
Advanced joining technology for the production of highly stressable lightweight structures, with fiber-reinforced plastics and metal
}

\author{
Holger Seidlitz ${ }^{1)}$, Felix Kuke ${ }^{1)}$, Nikolas Tsombanis ${ }^{1)}$ \\ 1) Department of Lightweight Structures and Structural Materials, fg-leichtbau@b-tu.de, Brandenburg \\ University of Technology Cottbus-Senftenberg, Konrad-Wachsmann-Allee 17, 03046 Cottbus, \\ Germany
}

\section{Keywords}

Automotive, CMT-Welding, Composite, Joining, Metal

\begin{abstract}
Organic sheets made of fiber-reinforced thermoplastics can make a crucial contribution to increase the lightweight potential of a technical design. They show high specific strength- and stiffness properties as well as good damping characteristics, while being able to show a higher energy absorption capacity than comparable metal constructions. In addition, organic sheets provide good recycling capabilities. Nowadays, multi-material designs are an established way in the automotive industry to combine the benefits of metal and fiber-reinforced plastics (FRP). Currently used technologies for the joining of organic sheets and metals in large-scale production are mechanical joining and adhesive technologies. Both require large overlapping areas to achieve the desired joint strength and stiffness of the technical design. Additionally, mechanical joining is usually combined with "fiber-destroying" pre-drilling and punching processes. This will disturb the force flux at the joint zone by causing unwanted fiber- and inter-fiber failure and inducing critical notch stresses. Therefore, the multi-material design with fiberreinforced thermoplastics and metals needs optimized joining techniques that don't interrupt the force flux, so that higher loads can be induced and the full benefit of the FRP material can be used. This article focuses on the characterization of a new joining technology, based on the Cold Metal Transfer (CMT) welding process, that allows to join organic sheets and metals in a load path optimized design. This is achieved by realigning the fibers around the joint zone by the integration of a thin metal pin. The alignment of the fibers will be similar to load paths of fibers inside structures found in nature. A tree with a knothole is always going to align its fibers in principle stress direction. As a result of the bionic fiber design, high joining strengths can be achieved. The increase of the joint strength compared to blind riveting was performed and proven with stainless steel and orthotropic reinforced composites in tensile shear-tests, based on the DIN EN ISO 14273.
\end{abstract}

\section{Introduction}

To achieve weight reduction in the automotive sector, mainly materials such as aluminum alloys or high strength steels are used. A new material choice with rising demand in the industry is the use of fiberreinforced plastics (FRP). The synergy effects of plastics and metal lead to multi-material assemblies that are increasingly applied in the automotive industry [1]. Especially carbon-fiber-reinforced plastics with a thermoset matrix, which lead to multi-material-assemblies with benefits such as high stiffness and low weight, are used in the automotive sector. The new material mix is a big challenge for the joining technology since the different properties of the materials (e.g. stiffness, strength, thermal expansion, corrosion) need to be respected to get the intended results [2]. Applied technologies for the joining of FRP-parts with metal structures are frictional and form-locking joints as well as adhesive joints, whereby for these technologies the joining components need to be prepared in a complex way. This includes the 
drilling or punching of holes for bolt- and rivet joints, as well as the preparation of the surfaces for adhesive joints by cleaning, etching, grinding or degreasing. Bolting is one of the most extensively used methods of joining composites and metals mechanically. Riveting is also used, although the rivet installation process can damage the composite laminate inside the fastener hole. This is caused by the expansion of the rivet shank to form an interference fit [3]. Regardless of this fact, the latest BMW 7 series, as well as the Audi R8 e-tron, uses the blind-riveting technology to join the components (figure 1). Drilling and punching with cut section leads to unwanted fiber-destruction and inter-fiber failure [4]. This interrupts the force flux within the fibers and induces critical notch stresses into the joining areas. With these limitations, the full potential of the lightweight-design is not fully used [2],[3,5,6]. To compensate the occurring notch stresses in the load inducing areas, bigger overlapping areas between the metal and FRP components combined with bigger wall thicknesses are needed to fulfil the strength requirements of the joint.

a)

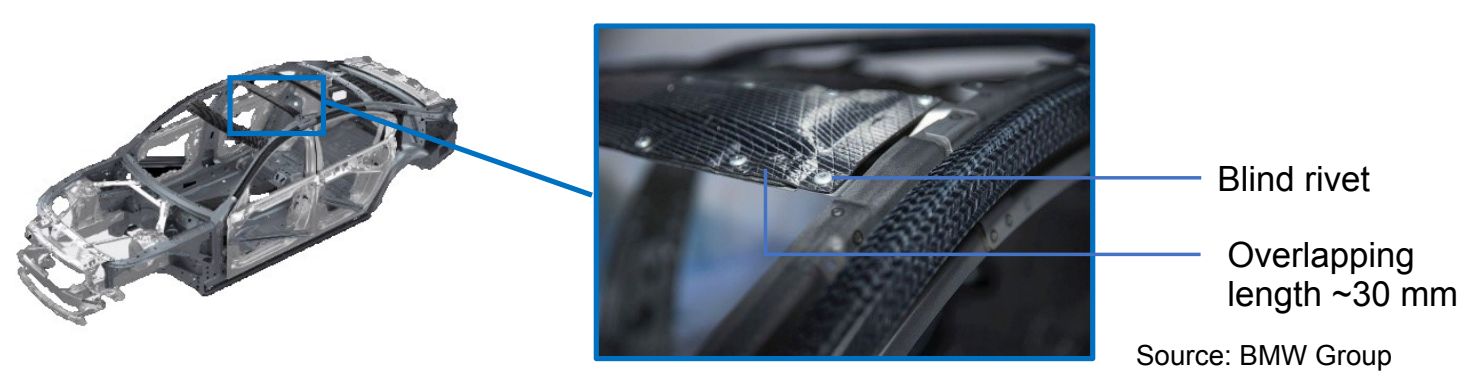

b)

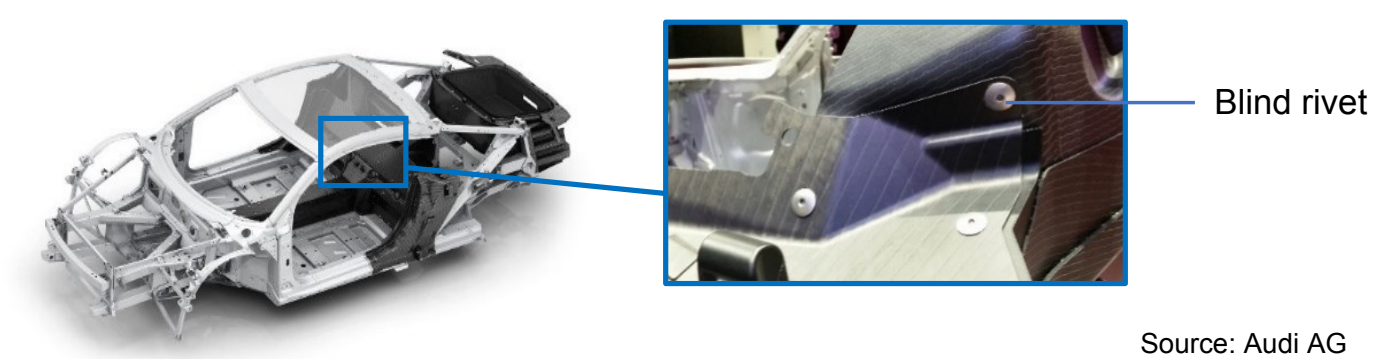

Figure 1: Application of blind riveting in the car body construction to create FRP and metal hybrid components, a) in the new BMW 7 series, b) in the Audi R8 e-tron

Currently, thermoset based FRP-materials are consolidated to final parts within a few minutes. This leads to long production cycle times. In addition, they cannot be reshaped after the process. Compared to the long process of curing thermosetting matrix materials, finished parts can be made of preconsolidated thermoplastic FRP-semi-finished-products (Organic Sheets) in a few seconds. For this, the matrix needs to get heated up again to reversibly change its state of aggregation. As a result, load introduction zones can be formed subsequently, so that a severing of the fibers can be avoided [7].

A new joining concept, derived from the "Cold Metal Transfer Welding" (CMT), gives the decisive solution approach. This process allows the one-sided, fault-tolerant and fiber-fair joining of the different material groups in short cycle times. With this new joining technology, overlapping areas can be reduced as compared to usual riveting techniques. Furthermore, areas in which loads are introduced don't have to be reinforced. The new joining technology leads to weight advantages and makes use of the full potential of composites.

The increase of the joint strength when using pins instead of blind rivets is tested with specimens made of glass fiber-reinforced plastics (GFRP) with a thermoset epoxy resin matrix using the hand lay-up technique. 


\section{Bionical inspired load introductions for composite structures}

The analysis of design-principles in nature and their adaptation to defects or flaws in the construction helps when optimizing the design of joints. Trees try to maintain a constant stress distribution in a failure zone, such as cracks or decay [8]. The developing stress-overload gets reduced by adding additional or stronger material around the defect. As shown in figure 2, the tangential relocation of the wood fibers is used, so that the notch effect, caused by defects such as knotholes, can be countered to achieve a homogeneous stress distribution [9].

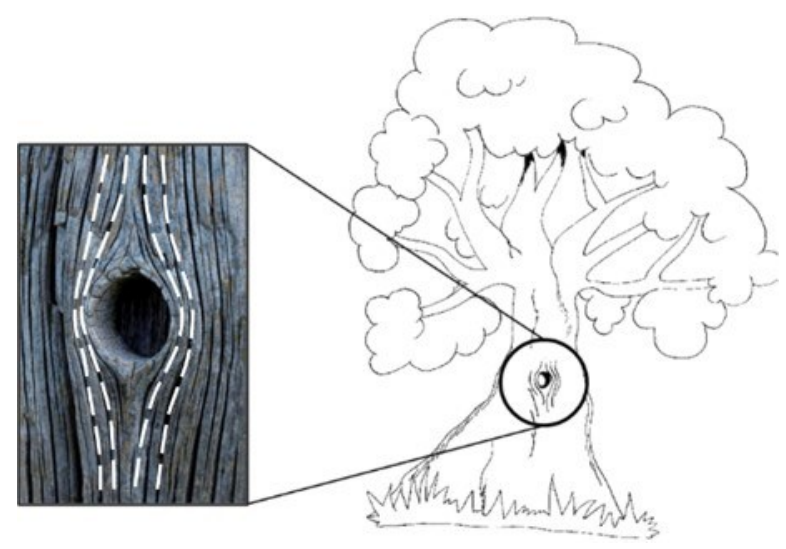

Figure 2: Reduction of the notch effect at knotholes by optimizing the orientation of the wood fibers

Wood fibers have their maximum strength- and stiffness properties when they are aligned along the principle stress direction. Therefore, the fiber orientation complies with the direction of the principle stresses. This results in less shear stress between the fibers and a higher strength of the material.

This construction principle of nature can be used for technical FRP-Applications to increase the strength at notch-sensitive areas of the component (e.g. at holes or cutouts) or at load inducing areas.

\section{Development of a CMT-Welding-Process for high bearable FRP/metal joints}

The patented joining technology, developed by the chairs "Department of Lightweight Structures and Structural Materials (LsW)" and "Joining and Welding Technique (LFT)" at the Brandenburg University of Technology Cottbus - Senftenberg [10], which is used for joining thermoplastic composites and metal sheets, can be suitable for economic large-scale production. A new process that is being developed is characterized by the potential to achieve short production cycles, an optimized flow of forces and high strength joining properties of the joining areas as well as a high usage of lightweight potential. It can be used in several industrial branches when it is optimized. The reduced overlapping lengths, while only having one-sided accessibility to the joining location, makes the new joining technology an interesting alternative for the automotive industry. In comparison to the typical joining methods, such as blind riveting, there are less problems when it comes to shifting/moving of tolerance zones since pre-drilling operations can be skipped. The pin-process is based on the Cold-Metal-Transfer-Welding technology and is characterized by its reversible welding wire feed. The welding wire gets welded onto a metal part and cut off at the desired spot by using an electrical impulse in combination with a pullback mechanism. The so-called pins are hence created. The CMT-Pin process and its possibilities are described in $[2,11]$. The joining with plastic materials is described in [2, 12]. An existing method to join metal- with plastic parts in a multi-stage process is the "Hybrid penetrative reinforcement process" (HYPER). In this process, the pins are welded onto the metal part and then pressed into a plasticized thermoplastic. In addition, the plastic can be secured by glue application [13]. The disadvantages of this solution are the needs of many process steps. This includes the application of the plastic material onto the pins, followed up by a glue application and the need of a press to maximise the joint strength.

Fiber-reinforced thermoplastic composites can be joined in a material-optimized way with cycle times suitable for large-scale production even after consolidation has taken place [10]. For this, the plastic matrix needs to be plasticized locally in the joining area. According to bionic principles, the reinforcing 
fibers can be relocated and optimized for the flow of forces by the joining element during the joining process. The relocation of the fibers at the joining area is shown in figure 3.

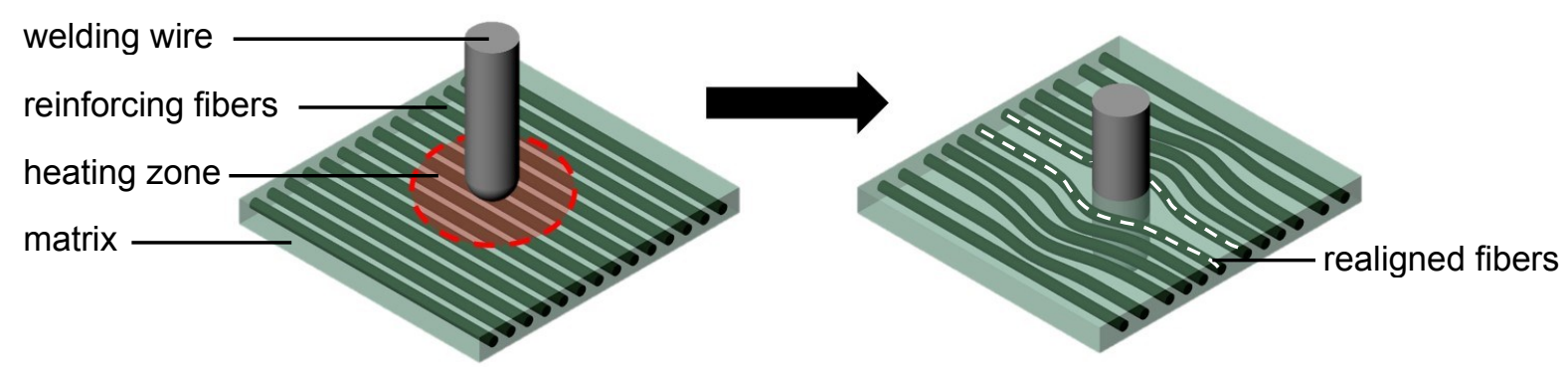

Figure 3: Joining area with optimized fiber orientation

Based on the principles of the thermomechanical drilling (radial displacement of the fibers), as well as the low-heated CMT-Welding, a new joining technology is developed to create highly durable hybrid FRP/metal-parts [14].

The joining process breaks down into three process-integrated steps, which are described in the following paragraphs and shown in figure 4 . The experimental setup is shown in figure 5.

\section{Preheating the welding wire and/or the FRP-joining-area}

In the first step, the thermoplastic FRP gets positioned, so that it overlaps with the metal part. The welding wire is transported into the joining-area through the welding torch. With an infrared heater, the FRP gets heated up until the specified melting temperature of the FRP-matrix is reached (figure 4a). The matrix is now partially plasticized. The fibers inside the FRP can be displaced by the insertion of the welding wire, so that the flow of forces in fiber direction is not interrupted. Damaging the fibers can almost be entirely prevented.

\section{Delivering the welding wire into the FRP with subsequent welding onto the metal sheet}

The welding torch pierces the plasticized thermoplastic FRP with the welding wire. Since the welding wire is comparatively thin $(1.0-1.2 \mathrm{~mm})$ and the FRP is heated up to the melting temperature of the matrix, the fibers will not be damaged but only be displaced by the welding wire. With a defined speed, the wire is moved towards the parts to be joined, so that it eventually pierces the FRP. Immediately after the welding wire contacts the metal surface, the welding process begins (figure 4b). Due to a high starting current, an electric arc is lit. Immediately after that, the current value is lowered, so that the welding wire melts off. The area where the welding wire is welded to the metal surface is called the pinbase. Moving the wire with a defined speed, combined with a forward and backward movement, the form of the pin-base is created. The welding process of the pin is dependent on the material of the welding wire, the welding wire diameter and the base material.

\section{Separating the wire by melting/forming the locking head}

Subsequently, the upper part of the wire is melted by an electrical separation-pulse, so that the melt droplet forms the locking head in the joining area on the FRP-surface (figure 4c). A pin with a locking head is created which connects the metal- and the plastic components. The locking head takes up the mechanical constraints by creating a form closure in the direction of the welding-wire-axis. 
(a)

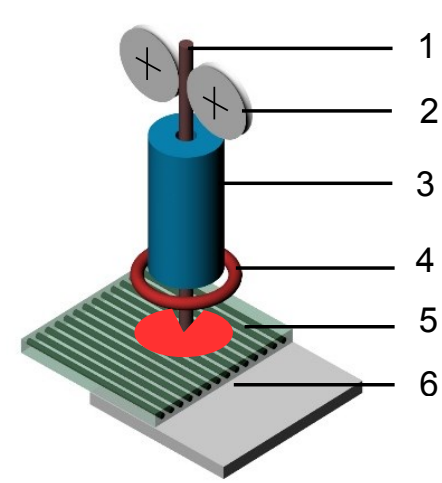

(b)

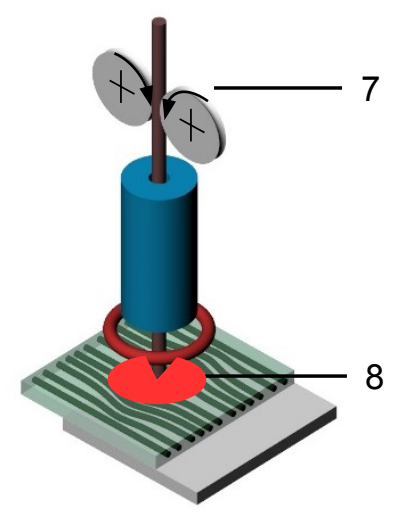

4 IR-emitter

5 FRP with reinforcing fibers

6 metal component (c)

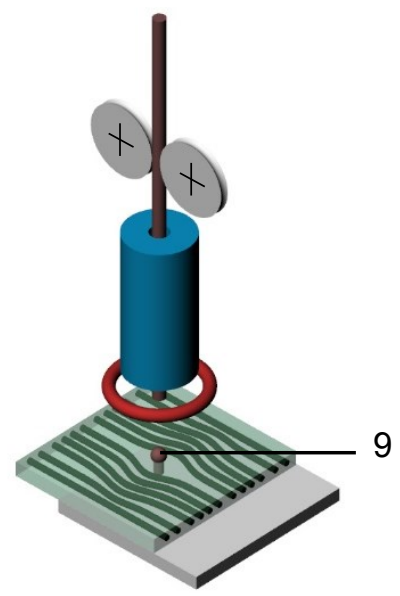

7 direction of wire transport

8 relocated reinforcing fibers

9 pin with locking head

Figure 4: Schematic view of CMT-Pin welding process

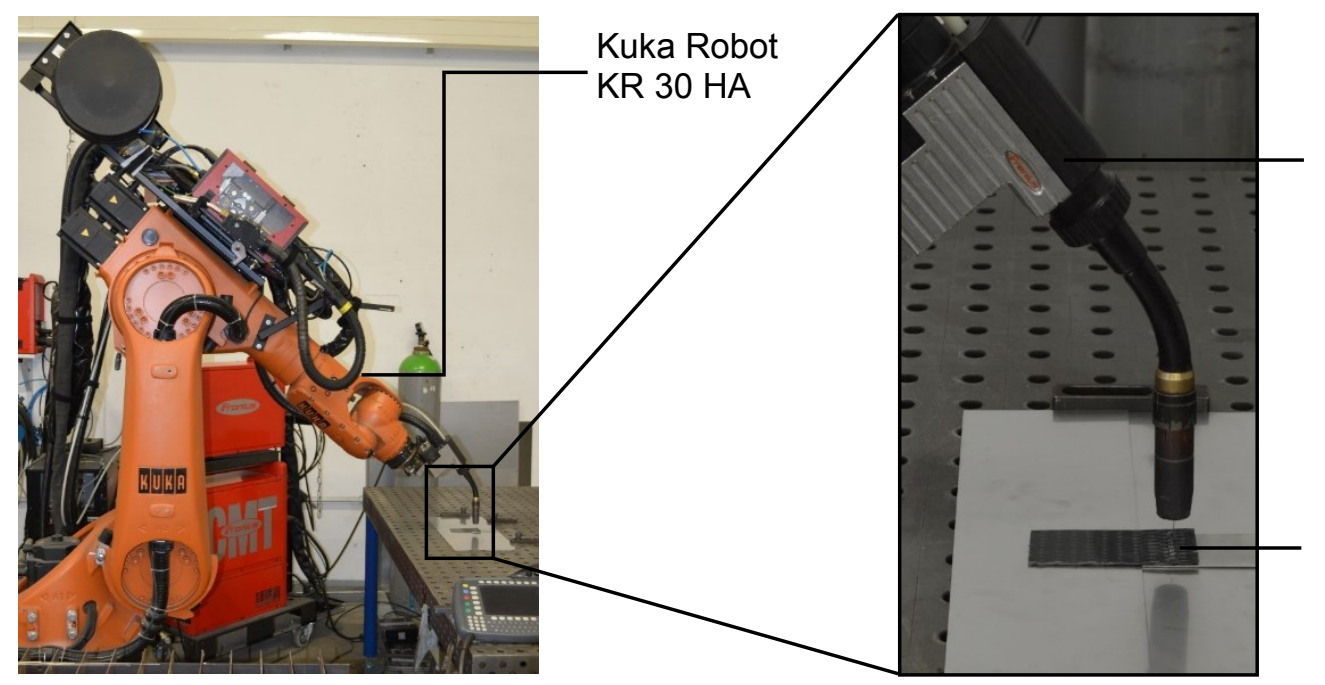

Fronius

welding torch

joining area for the FRP-/metal joint

Figure 5: Experimental setup for automated application of the pins

The CMT-Pin-Welding-Process, used to weld the pin and subsequently separate the welding wire, is dependent on the distance of the welding torch, the material of the welding wire and its diameter, the conveying speed of the wire and its direction (pullback) as well as the current-voltage-time-regime. Depending on the setup of the parameters, it is possible to form a locking head/ball on top of the pin. Besides sharpened/pointed or flattened tip-styles, it is also possible to form out the preferred ballgeometry [11]. The locking head can be formed directly above the surface of the FRP. As described in the previous paragraphs, the automated CMT-Pin-Welding-Process is going to be able to weld thermoplastic FRP with metals. The following tests are preliminary studies to determine if the new joining process delivers the demanded strengths. Therefore, the following tests use thermoset resin and the hand lay-up technique, instead of thermoplastic matrix and an automated process. 


\section{Development of a joint design with optimized pin arrangement}

The following chapters describe the cause-effect relationship between fiber-fair joining of composites and the consequential increasing of the specimen strength. By using the automated process, shown in chapter three, FRP/metal pin joints with thermoplastic matrix were produced in previous examinations. The created specimens are still in need of research and development as it was only possible to create up to 4 pins in a row. Furthermore, the specimens could not reach a sufficient joint strength. To better understand the mentioned cause-effect relationship and the mechanics of a pin joint, experimental studies with hand lay-up FRP/metal pin specimens and thermoset matrix were carried out and described in this chapter.

\subsection{Description of used materials}

To characterize and compare the strength and failure behaviour of FRP/metal pin joints with FRP/metal blind rivet joints (table 1), static pull-shear tests based on the DIN EN ISO 14273 were executed. $\mathrm{FRP} /$ metal pin samples were made of FRP with an epoxy matrix and 1.4301 stainless steel. For this, the hand lay-up technique was used. Pins were welded onto multiple metal components. A release agent was spread equally on a glass surface. The first layer of resin was applied by pouring it on the glass surface followed up by a distribution of the resin using a paint roller. The fibers are now positioned on the lined-up metal components on the glass table, pierced by the metal pins. Additional layers of glass fibers are pierced onto the pins and wetted thoroughly with epoxy resin and the paint roller. Subsequently, the remaining layers of E-Glas are added and wetted with epoxy resin to build up the laminate. Conclusively, the laminate is covered with separating foil, breather and a vacuum bag to be finally sealed with tacky tape so that vacuum can be drawn. After the resin has cured, the laminate is separated from the glass table and the samples are cut out.

Table 1: Data of the joining materials and components

\begin{tabular}{ll}
\hline Component & \multicolumn{1}{c}{ Data } \\
\hline FRP & fiber: E-Glas, $280 \frac{\mathrm{g}}{\mathrm{cm}^{3}}$, twill \\
& matrix: Epoxy resin (Epoxidharz $L, R \& G)$ \\
& laminate thickness $\mathrm{t}_{\mathrm{L}}: 2.0 \mathrm{~mm}$ \\
& number of layers: 6 \\
& fiber volume content $\varphi=35 \%$ \\
metal & a $=105.0 \mathrm{~mm} ; \mathrm{b}=45.0 \mathrm{~mm}$ \\
& steel: 1.4301 \\
& thickness $\mathrm{t}_{\mathrm{m}}=1.5 \mathrm{~mm}$ \\
& a $=105.0 \mathrm{~mm} ; \mathrm{b}=45.0 \mathrm{~mm}$ \\
pin & steel: 1.4316 \\
& diameter pin: $\mathrm{d}_{\mathrm{p}}=1.2 \mathrm{~mm}$ \\
blind rivet & galvanized steel $\&$ aluminum \\
& diameter rivet shaft: $\mathrm{d}_{\mathrm{s}}=5.0 \mathrm{~mm}$ \\
& diameter rivet head: $\mathrm{d}_{\mathrm{h}}=9.5 \mathrm{~mm}$ \\
\hline
\end{tabular}




\subsection{Hand lay-up FRP/metal blind rivet joints}

To compare the overall strength of the blind rivet and pin joining techniques, specimens with one and two blind rivets with overlapping lengths $L_{O}=35 \mathrm{~mm}$ were created and tested. Each sample type, either with one or two blind rivets, was produced with 6 layers of GFRP and a metal component. The used materials are shown in table 1.

Three samples were tested for each type of specimen. The specimens are described as a schematic view in figure 8 and shown in figure 9.

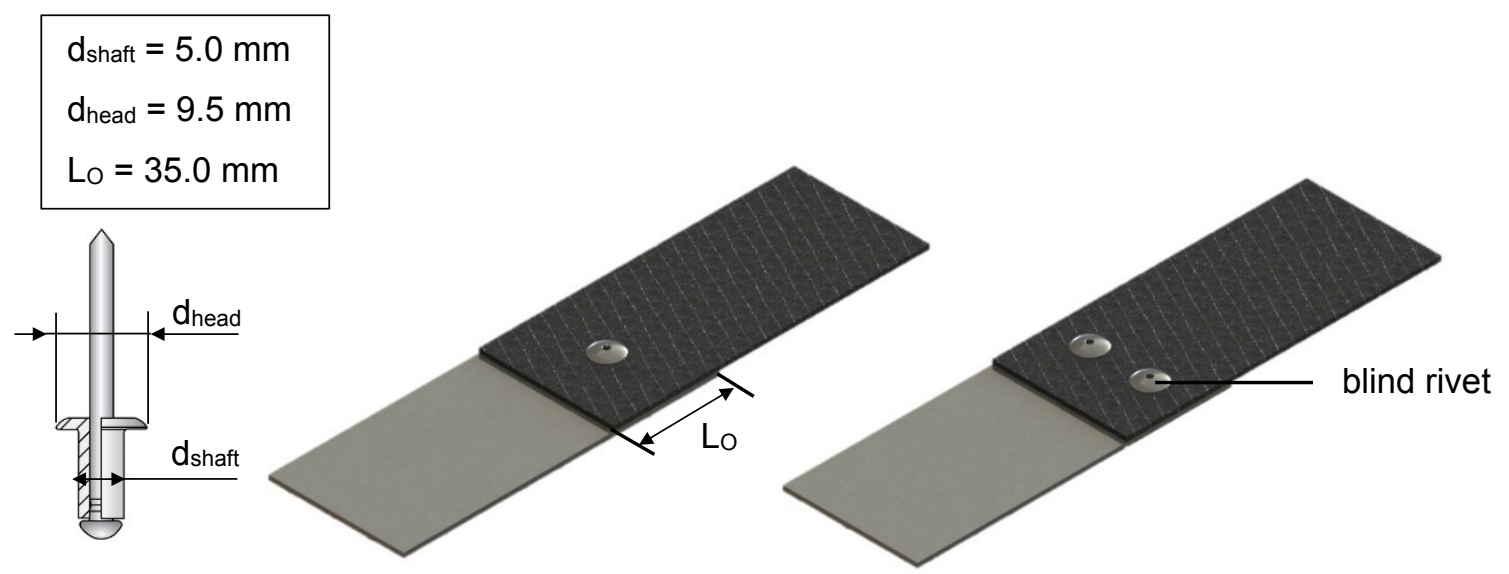

Figure 6: Schematic view of pin-specimens joined with one and two blind rivets
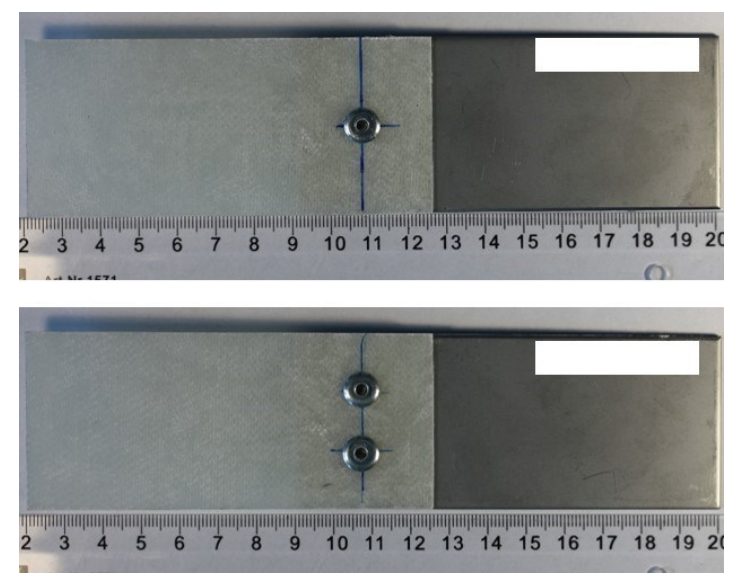

Figure 7: Specimens joined with one and two blind rivets

\subsection{Hand lay-up FRP/metal pin joints}

For the experimental studies, single-, two- and three-rowed pin-samples with overlapping-lengths $L_{O}=35.0 \mathrm{~mm}$ were created. The distance between the pins in every specimen type is $5.0 \mathrm{~mm}$. Figure 6 shows a single-rowed pin sample which is defined as "Type A". 


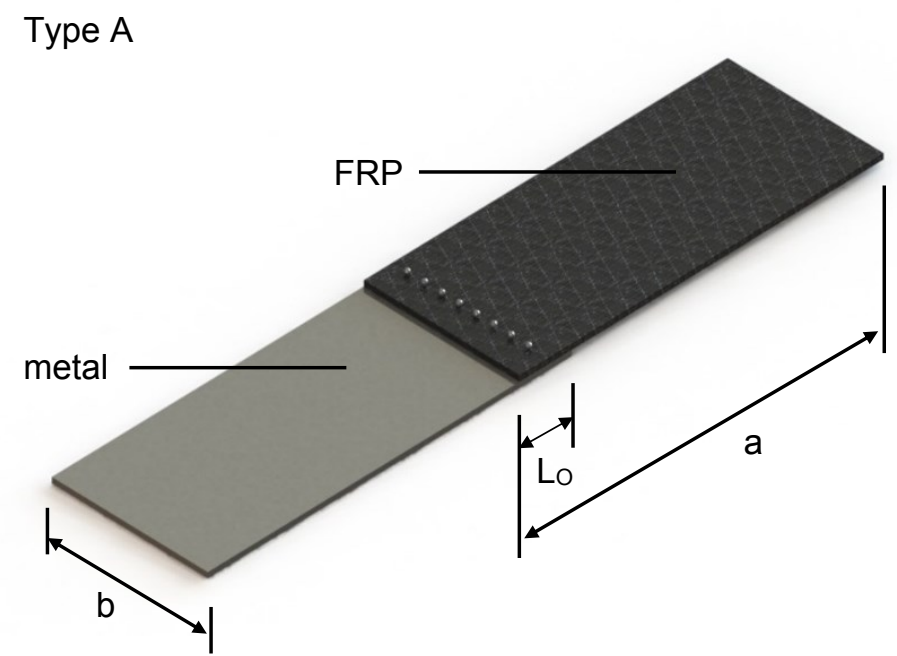

Figure 8: Schematic view of single-rowed pin-specimen, "Type A"

Figure 7 shows the two- and three-rowed specimens, "Type B" and "Type C", with overlapping lengths $L_{O}=35.0 \mathrm{~mm}$ respectively.

$\begin{array}{ll}\text { Type B } & \text { Type C }\end{array}$

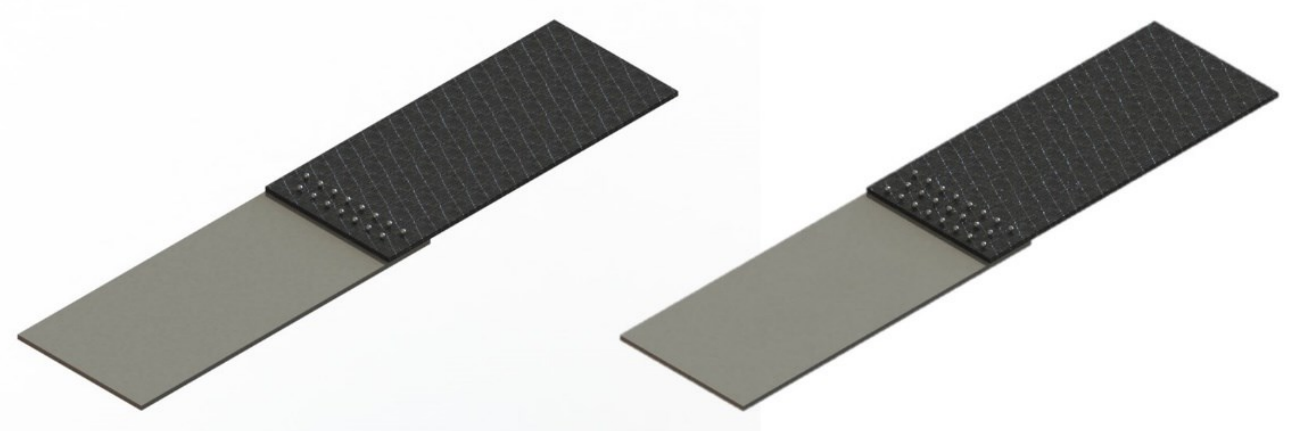

Figure 9: Schematic view of pin-specimens, "Type B" and "Type C"

\section{Characterization of hand lay-up FRP/metal rivet and pin joints}

\subsection{Basic strength tests}

The blind rivet and pin specimens were tested with an "Instron ElectroPuls E10000" testing-machine, using a traverse speed of $2 \frac{\mathrm{mm}}{\mathrm{min}}$. The test results of the blind rivet specimens are shown in figure 10 . In every sample, the FRP was the failing component. This leads to an unpredictable failure behaviour of the joint and dispersion of the experiment results. 


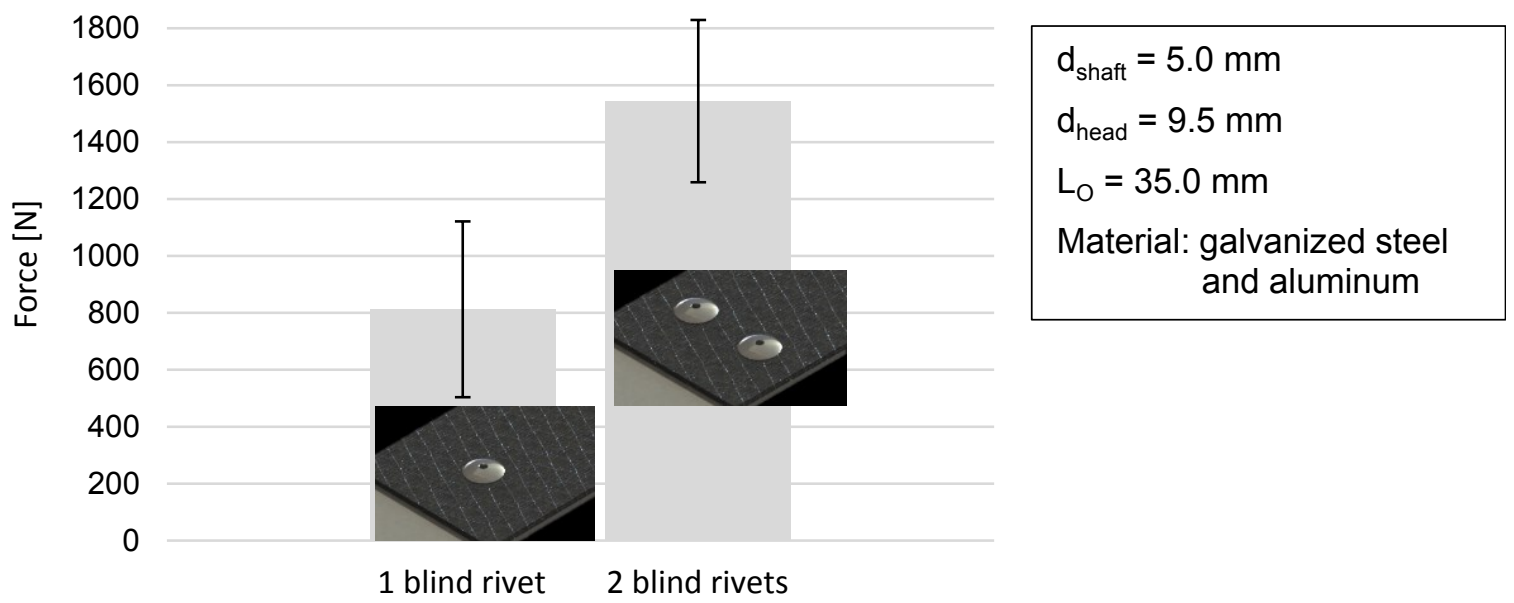

Figure 10: Static pull-shear test results of one and two blind rivets

As described in chapter 4.3, the FRP/metal pin specimens are categorized into three types. Each type of joint was tested with 4 specimens. The results are shown in figure 11. The dispersion of the pin specimen test results is lower than the dispersion of the rivet test results. This is caused by the failure behaviour of the samples. When the stress exceeds the maximum joint strength, the metal pins start to deform. This behaviour occurs, before the FRP starts to fail. The plastic deformation of the metal pin thus leads to a smooth and predictable failure behaviour with similar test results in every specimen group.

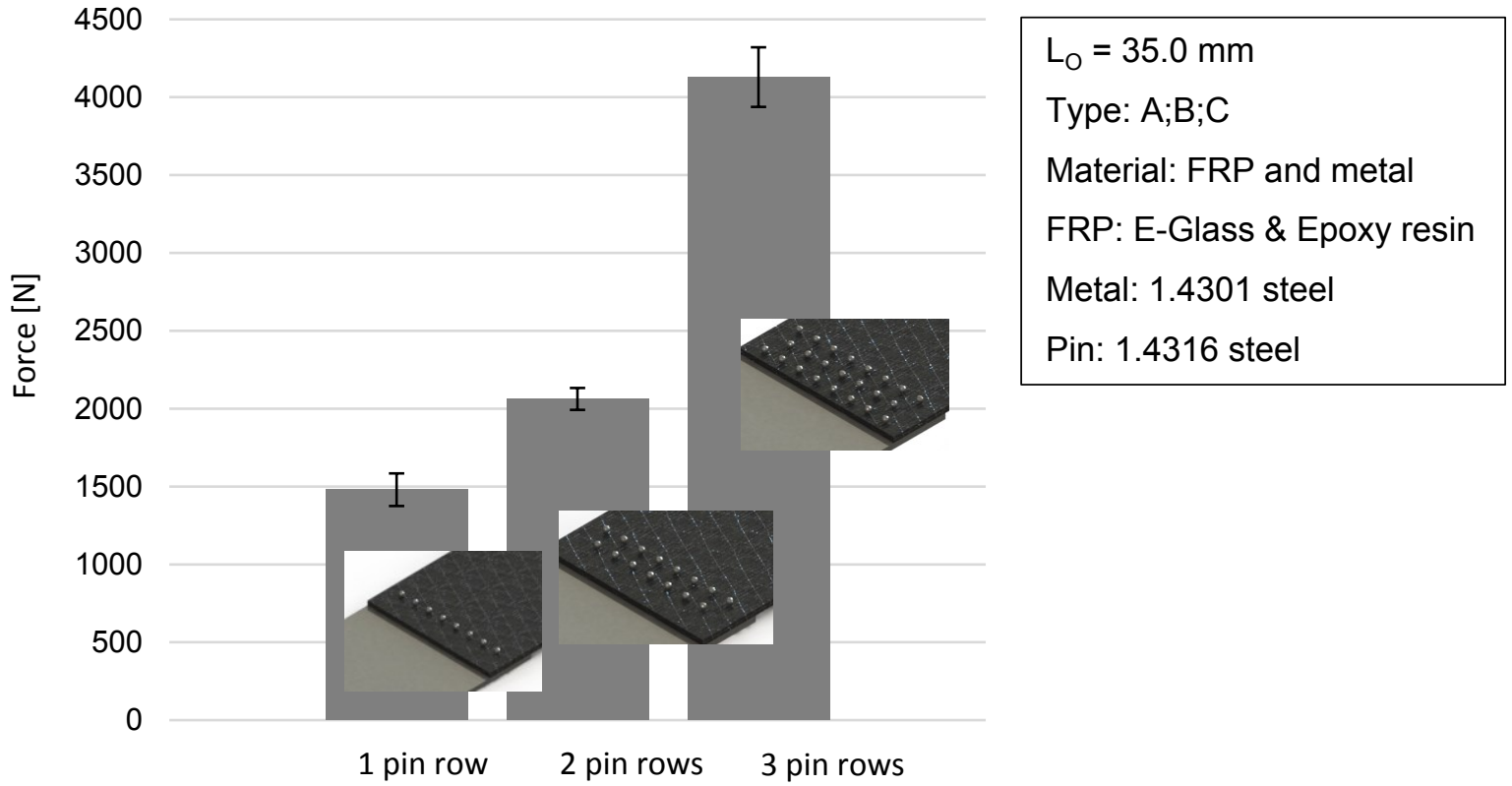

Figure 11: Static pull-shear test results of each pin-specimen type

To compare the pin with the blind-riveting joints, the strength of the blind riveting samples and the pin samples are compared in figure 12. In comparison, the specimen types joined with the pin technology show a higher maximum strength than the blind rivet samples. 


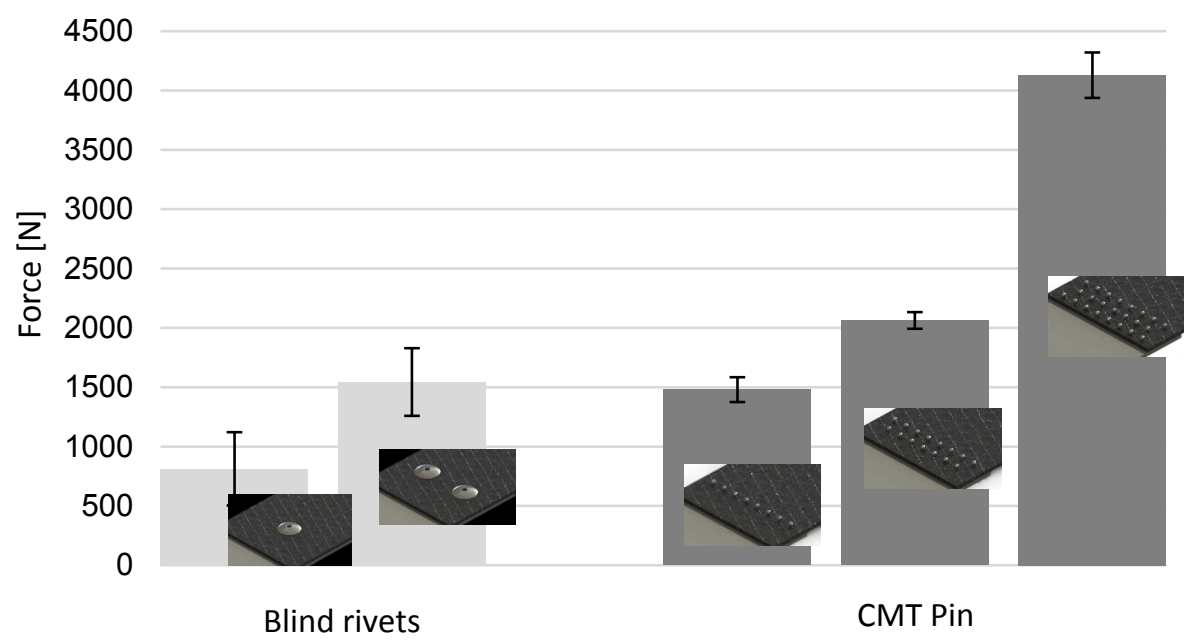

Figure 12: Comparison of the static tensile shear test results

\subsection{Analysis of the textile architecture}

To receive a view of the re-oriented reinforcing fibers, a non-destructive analysis of a representative joint with a composite part was done by using a microcomputer tomograph (Micro-CT) BRUKER SkyScan 1172. Since the metal and GFRP parts have vastly different densities, the metal pin had to be removed out of the joining area to be able to get a depiction of the fibers in high quality.

The micro-CT scanned the sample for $5 \mathrm{~h}$ and delivered a resolution of $5 \mu \mathrm{m}$ and a radiography of at least $47 \%$. Figure 13 shows the FRP component after being separated from the metal component.
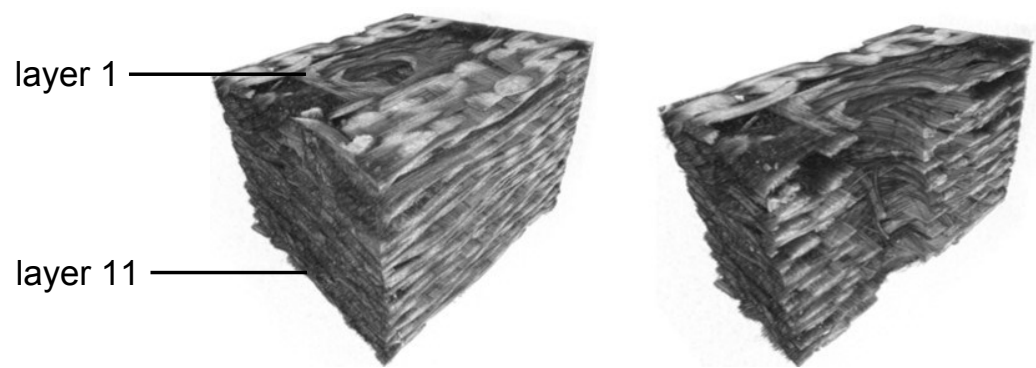

Figure 13: Fiber analysis of the FRP component using a computed tomography scan

Figure 13 shows the eleven layers of the FRP fabric at the joining area of the pin. The software NRecon was used to transform the $\mathrm{x}$-ray data to $2 \mathrm{D}$ images, which then could be processed by the software CTAnalyse. All of the reinforcing fibers are optimal displaced at the joining location and therefore respect the flow of forces. A breaking of the fiber could be avoided to the greatest possible extent. 

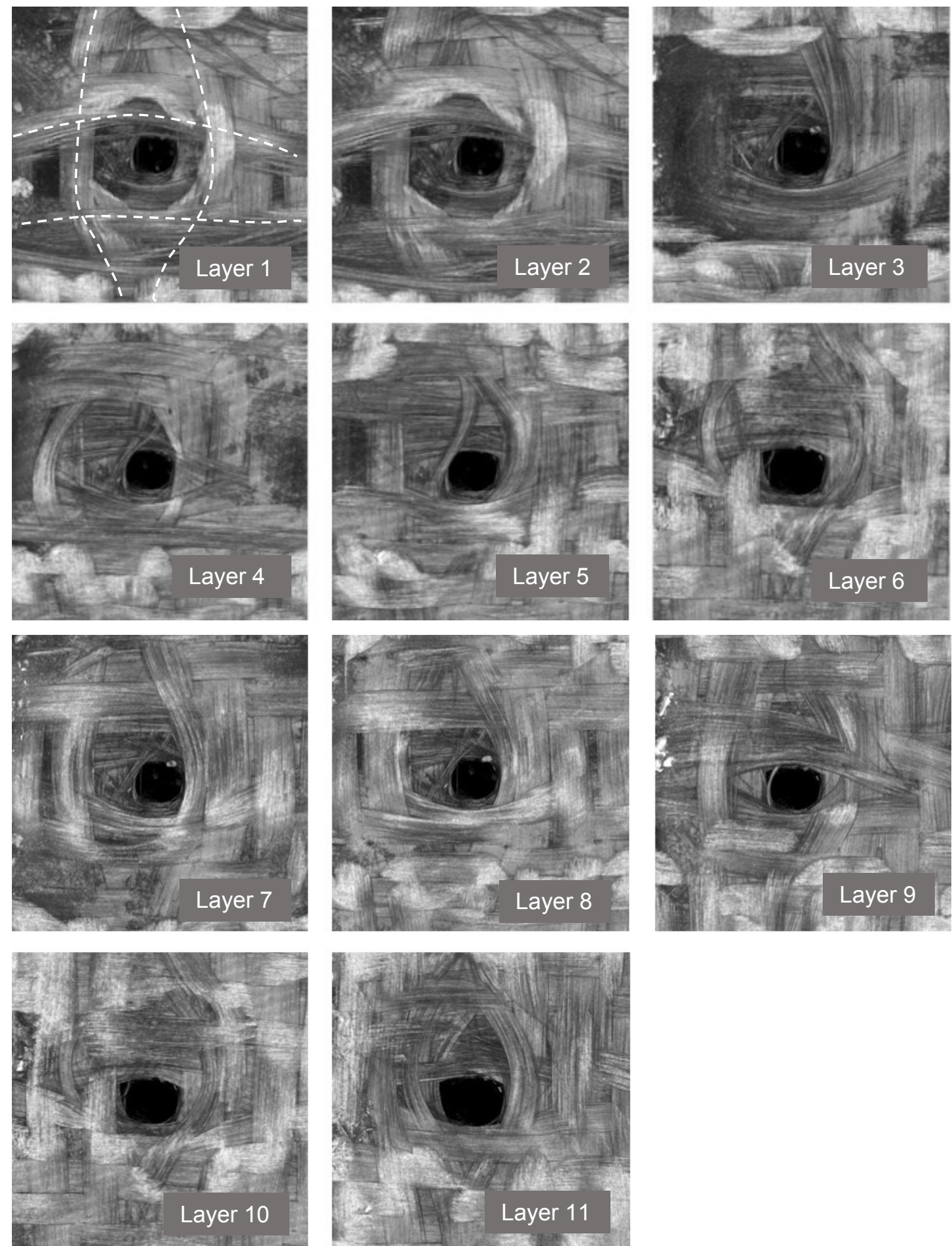

Figure 14: Detailed CT-Scans of the FRP joining area, layer 1-11

\subsection{Influence of the overlapping length $L_{\circ}$ on the strength properties of the specimens}

To characterize the ability of the new joining process to deliver high joining strengths, even with short overlapping lengths of the joining components, static pull-shear tests based on the DIN EN ISO 14273 were executed. Samples were made out of FRP with an epoxy matrix and 1.4301 stainless steel as the joining component (table 1). The rivet specimens consist of the same FRP and stainless-steel components but are joined with blind rivets instead of pins. For the experimental studies, single-, twoand three-rowed pin-samples with overlapping lengths $L_{O}$ ranging from $20.0 \mathrm{~mm}$ to $5.0 \mathrm{~mm}$ were created. The distance between the pins in every specimen type is $5.0 \mathrm{~mm}$. The experiments were performed on an Instron ElectroPuls E10000 with a traverse speed of $2 \frac{\mathrm{mm}}{\mathrm{min}}$. The following diagram 
shows the maximum strength of the hand lay-up FRP/metal blind rivet joints when varying the overlapping length $L_{O}$ from $20.0 \mathrm{~mm}$ to $5.0 \mathrm{~mm}$. It is striking that the maximum strength of the samples is reduced when the overlapping length $L_{O}$ gets lowered.

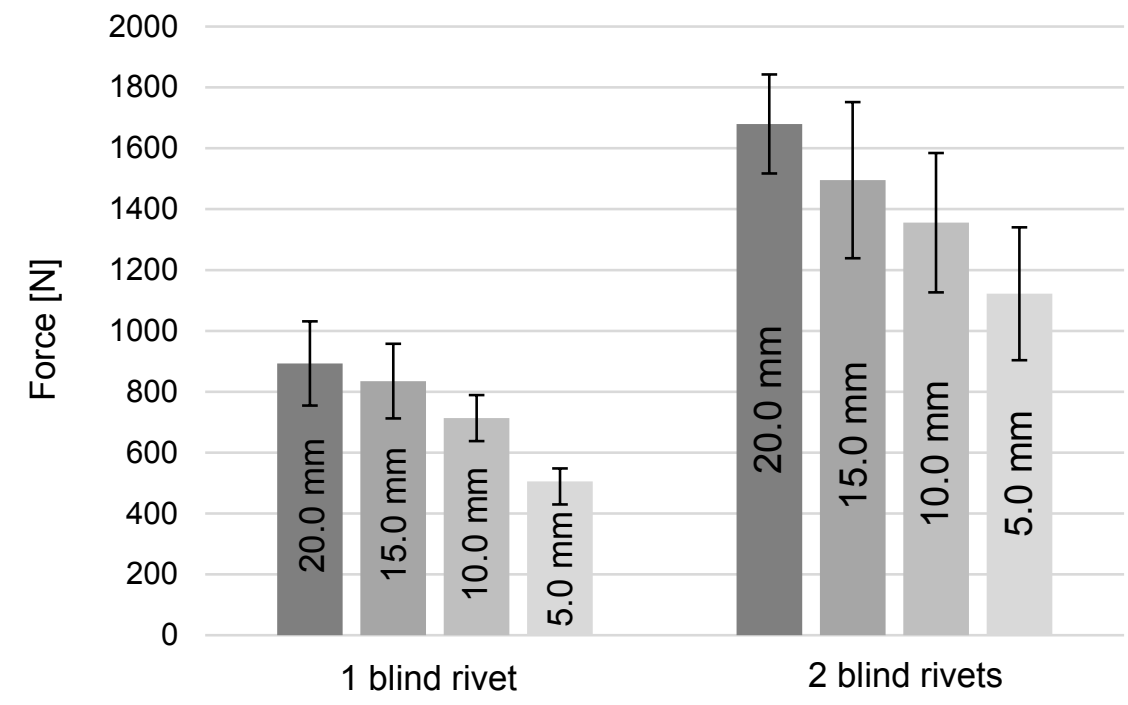

Figure 15: Static pull-shear test results of the blind rivet joints with varying $L_{O}$

In comparison, one can see that the strength of the pin joints does not decrease when the overlapping length $L_{O}$ is reduced. It is possible to achieve the same strength with an overlapping length $L_{O}$ of 5.0 $\mathrm{mm}$ as compared to an $L_{O}$ of $20.0 \mathrm{~mm}$.

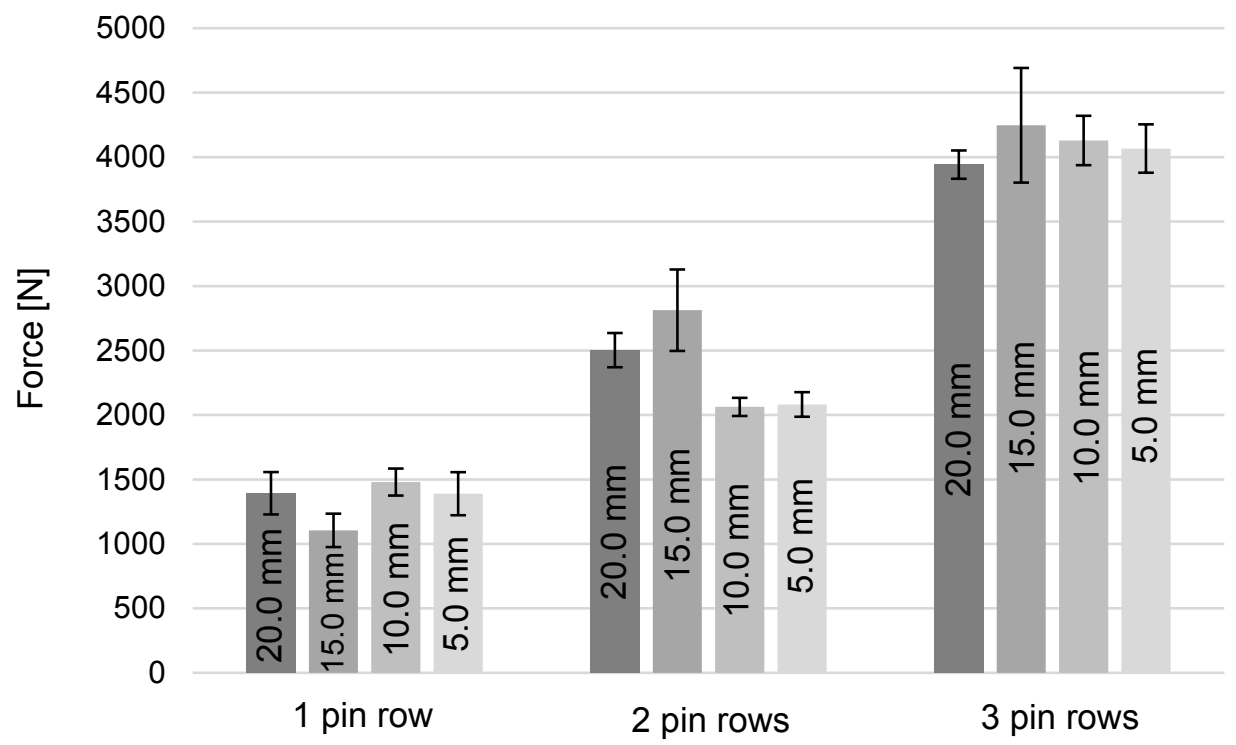

Figure 16: Static tensile shear test results of the pin joints with varying $L_{O}$

\subsection{Discussion}

The results of the tensile shear tests show that the strength of a pin joint does not decrease when the overlapping length $L_{O}$ is lowered. This is caused by the pin joint behaviour, which can be treated as a moulded-in hole. Moulded-in holes are stronger than drilled holes when the edge distance is small. If the edge distance is large, moulded-in holes have about the same strength as drilled holes [15]. This 
gives huge benefits when it comes to the design of the part, since overlapping lengths can be reduced and therefore unwanted material, which would lead to additional weight, can be omitted. Besides the weight advantage, it can be observed that the overall strength of the pin joints is higher than the blind rivet joints. This is caused by the lower notch stress that is induced when using the pin joining technique. The fibers are relocated around the joining element instead of getting destroyed by a pre-drilling process and therefore experiencing less notch stress. The pre-drilling operation for the blind rivets leads to delamination which encourages cracks and additional notch stress. This mechanism of delamination describes the damage that likely occurs in the interlaminar region between the adjacent layers of a laminate. Delamination can be influenced by the resin type and mechanical properties such as interlaminar fracture toughness, elastic modulus or the Poisson ratio. It is divided into push-down and peel-up of the plies. Peel up is caused by the abraded and cut materials that are getting pushed to the surface while drilling. The push-down effect is caused by the compressive thrust force that the drill induces into the laminate. If a diamond drilling tool with a special geometry that lowers the thrust force is used, the delamination damage can be reduced [16]. For the experiments that were mentioned in this paper, a Holex $6.0 \mathrm{~mm}$ HSS Jober drill tool was available. As this is not a special tool to drill composites, it is very likely that delamination damage around the drilled hole is existent and as a result is responsible for the lower strength of the blind rivet joint in comparison to the pin joint. Delamination leads to less strength and therefore an easier failure of the sample, especially when low overlapping lengths such as $\mathrm{L}_{\mathrm{O}}=5.0 \mathrm{~mm}$ are chosen.

\section{Summary and Outlook}

Shear-pull tests, based on the DIN EN ISO 14273, were performed for CMT pin and blind rivet joints. It was examined and proven that the fiber-fair relocation of the reinforcing fibers around the pin element has a positive impact on the strength of the joints. By using fiber-destroying pre-drilling processes to join the metal and FRP components with blind rivets, the strength of the joint is going to be lowered noticeably. In addition, the overlapping length $L_{O}$ of the pin joints can be reduced dramatically without having any negative impact on the strength of the joint. This gives huge benefits when it comes to the design of the part and leads to an utilization of the full benefit of the FRP material. Additional overlapping material, which would lead to additional weight, can be omitted. The pin joining process provides huge potential to join composites and metals in a load path optimized way with automated processing. Subject of further examination will be the optimization of the welding parameters for the automated joining process. The latest challenge is the reduction/elimination of the distance between the components to be joined. This distance was initially introduced to improve the ignition capability of the electric arc after the FRP was pierced by the welding wire. Furthermore, a new infrared spot in combination with a power controller and a radiation pyrometer makes it possible to gain more control of the heating phase and optimize the time and quality of the heating cycles.

\section{References}

[1] Lambiase, F.; Durante, M.; Di Illio, A.: Fast joining of aluminum sheets with Glass Fiber Reinforced Polyper (GFRP) by mechanical clinching. J. of Mater. Proc.Tec., 23 (2016), pp. 241251. doi: 10.1016/j.jmatprotec.2016.04.030

[2] Hackl, H.; Bruckner, J.: Auswirkungen des Multimaterial-Leichtbaus auf die Fügetechnik. ATZ Automobiltechnische Zeitschrift, 10 (2013).

[3] Joesbury, A. M.: New approaches to composite metal joining. Cranfield University, 2015.

[4] Collins, M. W.; Brebbia, C. A.: Design and Nature II: Comparing Design in Nature with Science and Engineering. Southampton: WIT Press, 2006.

[5] Osiecki, T.; Seidlitz, H.; Gerstenberger, C.; Kroll, L.; Scholz, P.: Customized Metal/Composite Hybrids for Automotive Applications. In: AutoMetForm - SFU 2014, new materials for vehicle components, November 3rd to 5th 2014, Freiberg, Saxony, Conference proceedings, 2014, pp. 29-36.

[6] Seidlitz, H.; Kroll, L.: Hochfeste Mischbauweisen mit thermoplastischen Faserverbunden und Metallen. Joining Plastics - Fügen von Kunststoffen, 8 (2) (2014), pp. 106-111.

[7] Seidlitz, H.; Winter, L.; Kroll, L.: New Joining Technology for Optimized Metal/Composite Assemblies. J. of Eng., 2014.doi: 10.1155/2014/958501 
[8] Seidlitz, H.: Entwicklung von kraftflussgerechten Verbindungstechniken für Mischbauweisen mit thermoplastischen Faserverbunden und Metallen. München: Verlag Dr. Hut, 2013.

[9] Mattheck, C: Bauteiloptimierung nach dem Vorbild der Natur. In: VDI Fachtagung, Baden-Baden, 2013.

[10] Seidlitz, H., Michailov, V. and Schleuß, L. (2015) Verbindungstechnik für Verbundkonstruktionen aus Metall und FVK/Brandenburgische Technische Universitat Cottbus-Senftenberg. DE Patent No. 102015114511.1

[11] Stieglbauer, W.; Kazmaier, J.: Innovative, multifunctional, form-locked joining technology for dissimilar material combinations. In: DVS BERICHTE, 100-103, Schweissen \& Schneiden; Die Verbindungs-Spezialisten 2009: Vortrage der Veranstaltung in Essen vom 14. bis 19. September 2009, Düsseldorf: DVS Media, 2009.

[12] Juliana Schulze, „Metall mit organischem Material verpinnen,“ 08.12.2009. [Online]. Available: https://www.konstruktionspraxis.vogel.de/metall-mit-organischem-material-verpinnen-a-242729/. [Access on 22.02.2018].

[13] Schürmann, H.: Konstruieren mit Faser-Kunststoff-Verbunden. Berlin: Springer, 2007.

[14] Klein, M.; Podlesak, F.; Höfer, K.; Seidlitz, H.; Gerstenberger C.; Mayr, P.; Kroll, L.: Advanced Joining Technologies for Load and Fibre Adjusted FRP-Metal Hybrid Structures. J. of Mater. Sci. Res., 4(4) (2015).pp. 26-33. doi: 10.5539/jmsr.v4n4p26

[15] Lin, H. J.; Tsai, C. C.: Failure analysis of bolted connections of composites with drilled and moulded-in hole. Compos. Struct., 30(2) (1995), pp. 159-168. doi: 10.1016/0263-8223(94)00040-9.

[16] Durao, L. M. P.; Tavares, J. M. R. S.; de Albuquerque, V. H. C.; Marques, J. F. S.; Andrade, O. N. G.: Drilling Damage in Composite Material. Materials, 7(5) (2014), pp. 3802-3819. doi: $10.3390 / m a 7053802$ 